\title{
Ecological Consciousness in a Shift of Scientific Paradigms
}

\author{
Mariya Yazevich, ${ }^{1,}$, Oksana Kalinina ${ }^{2}$, and Olga Zhironkina ${ }^{3}$ \\ ${ }^{1}$ T.F. Gorbachev Kuzbass State Technical University, Rector, 650000, 28 Vesennyaya St., Kemerovo, \\ Russia \\ ${ }^{2}$ Tomsk Polytechnic University, 634050 Lenin Avenue 30, Tomsk, Russia \\ ${ }^{3}$ Kemerovo State University, 650000, 6 Krasnaya st., Kemerovo, Russia
}

\begin{abstract}
The analysis of the relationship between environmental conscious and scientific paradigms in different Western civilization development periods is presented in the article. The peculiarities of the influence of classical, non-classical and post-non-classical science on the types of environmental conscious characteristic of modern and postmodern societies are studied. The provision on the existence of the connection between the logical and philosophical attitudes of the New European (classical) science and the formation of the principles of anthropocentric environmental conscious that have ensured the formation of the anthropogenic civilization is proved. It is determined that within the framework of the non-classical paradigm the theoretical and philosophical foundations of the eco-centric model of environmental conscious begin to take shape. In the post-non-classical era the model of eco-centrism and worldview orientations directed to the development of the strategy for the safe interaction of nature and man is being formed on the basis of the theories of postmodernism and under the influence of modern cognitive practices. The influence of ontological and epistemological attitudes dominating within the framework of scientific paradigms on the formation of principles of nature management in anthropocentric and eco-centric systems of ecological conscious is traced.
\end{abstract}

\section{Introduction}

The aggravation of global environmental problems in the twentieth century has provoked a need for understanding the causes and sources of environmental crises. Awareness of the lack of prospects for the anthropogenic civilization and the need to develop a constructive strategy for the development of society made it necessary to create a new model of relations in the system of nature-society, ensuring their harmonious and holistic coexistence. At the same time, great importance in overcoming global contradictions and leveling negative trends from human activities is attached to the development of a worldview attitude capable of providing civilization with new guidelines in relation to the environment and the principles of effective nature management.

\footnotetext{
* Corresponding author: maria762003@list.ru
} 
Understanding the relationship between environmental crises and the mental attitudes of society involves addressing the problem of human-nature interaction, as well as their conceptual interpretations, characteristic of certain epochs. Socio-natural relations are mobile, are transformed in the course of historical development and are conditioned by various causes: from individual and social needs, cultural traditions to specific cognitive practices, epistemological attitudes and ontological prerequisites that dominate in a certain epoch. In this regard, it should be noted that the formation of worldview orientations that contributed to the development of environmental crises is largely associated with the emergence of the phenomenon of scientific knowledge in the modern era in Western European society.

\section{Materials and methods}

For research of features of interrelation of ecological consciousness and scientific paradigms researches were used: J. E. Baugher, F. Capra, I. V. Chernikova, R. Rorti, V. S. Stepin, J. Habermas, M. Foucault, L. P. Pojman, P. Pojman, C. Weston and others. This made it possible to cover all the important stages in the development of science and environmental worldview, to reveal their correlation. For determination of features characteristic for different periods of science and types of ecological consciousness, and also identification of their General principles methods were applied: rational and logical analysis, structural and functional approach, conceptual analysis, historical and logical.

\section{Results and discussion}

The emergence and spread of science became the source of modern anthropogenic civilization and determined the formation of a certain type of ecological consciousness, which ensured the development of both an industrial boom in Western society and associated negative environmental processes. Environmental conscience is an intellectual and spiritual prerequisite for the formation of social practices that include environmental knowledge, concepts, categories, principles, ideas, theories, and an established model of ecological behavior and manifests itself in certain intentions, actions, providing ways to interact nature and man development of nature, conservation of the biosphere, use of resources, environmental safety, etc.). [1]

The genesis of the environmental conscience of anthropogenic civilization begins in pre-modern societies, but its active development falls on the epoch of modernity and is closely connected with the classical scientific paradigm. In the opinion of the V.S. Stepin, the reasons for the eco-crisis relations are not easy in the imperfection or mismanagement of technology, they are laid in the deeper foundations of modern society. This refers to the characteristics associated with the emergence and establishment of a specific new European mechanism for the development of culture, a mode of activity that includes, in particular, such an attitude towards nature, humanity, such a system of value determination of its behavior that, in appropriate socio-historical conditions, could not exacerbate environmental relations. [2]

The emergence of science occurs in the era of modern times in the conditions of transformation of traditional ideas about the structure of the world and society, the source of which were the logical and philosophical attitudes of the ancient and medieval world view. In the conditions of changing philosophical and ideological orientations (secularization processes, Reformation, the emergence of Protestant ethics and anthropology, the transition from cosmocentrism and theocentrism to anthropocentric ontology, the manifestation of symptoms of axiological anomie, the modernization of social 
practices, etc.), the classical model of science and the development of anthropogenic civilization attitudes. The basis for describing the reality of modern European science is the idea that explains the world order as a single mechanism consisting of moving material elements (atoms), obeying objective universal laws and principles, as well as devoid of hierarchy, ethical meanings and value measurement. All the differences in material nature (inherent in the ancient medieval view of the world) are absent in this picture of the world: any element of the created nature is in principle equal, more accurately equal to any other, and the whole creation, if it is considered separately from the Creator, is unified.

The comprehension of natural laws presupposed the discovery of cause-effect relationships in the phenomena of nature through a properly organized methodology (observation and mathematical calculation). At the same time, the prevailing Cartesian model of cognition prescribes the original ability of the human consciousness (subject) to think in accordance with the logic of the existence of the world (object). The main way to obtain a reliable knowledge of nature is experimental research, which is based on mindcontrolled observation and measurement. This methodological setting stimulated not only the extensive growth of natural theories, but also the design of a new system of views on nature, where the world around is losing its "sacredness" and becomes a "great mechanism", a "machine", comprehensible through a set of measuring practices.

The unfolding of empirical epistemology based on the principles of logocentrism promoted the formation of subject-object relations, where the autonomous subjective consciousness cognizes fragments of reality through experience and logical procedures, creating theoretical constructions-projections that explain and model the surrounding reality in accordance with the specifics of one's own consciousness. [3] In this case, the subject opposed to the object becomes not just a participant in cognition, but the creator of reality, the basic ontological unit with the help of its own mind, providing the reality of the external world. He does not simply discover the laws of the universe, but encodes being, formalizes in theory, and initiates practices that make it possible to extract from nature a benefit on an "industrial" scale. This metaphysical setting becomes the basis for the anthropocentric picture of the world where, by setting the measure of what is, the person prescribes laws to nature, receiving the status of her master and the moral right to change reality according to her own understanding.

Of particular importance in the classical scientific paradigm is the idea of progress, on the basis of which an interpretation of natural laws is formed. Progress was understood as a movement similar to a mechanism that can be studied, predicted, managed, and consciously directed. The doctrine of progress justified the statement about the evolutionary development of the biosphere and determined the intervention of man as a necessary factor for the optimization and balance of natural processes. The idea of progress presupposed the activity of a sovereign subject endowed with reason and rights, carrying out activity in all spheres of the external world from epistemological practices to social modernization. As a result, progressism becomes the dominant conviction in the modernist picture of the world and prescribes the existence of a relationship: technological progress - material progress progress in human rights. Thus, in the public consciousness, an instinct for subjugation, the transformation of nature, the subordination of it to human understanding was formed, and its justification was the idea of progress, which gained supremacy in the worldview of the Enlightenment.

It should be noted that the epoch of modern science is characterized not only by the fact that the values of society in relation to nature change (ethical and aesthetic views of the ancient and medieval installations are replaced by material and pragmatic ones), but also because in connection with such a transformation of public views, soon there was a need for conservation. But concern for nature does not arise with the purpose, for example, of preserving aesthetic characteristics or reverence for "God's creation," but for continuing the 
"productive" exploitation of nature and extracting the maximum profit from it. At the same time, nature conservation activities that were dictated by the principles of pragmatism were not excluded. So a person should save the natural environment so that future generations could use it.

Within the framework of the logical worldview of the classical scientific paradigm, an anthropocentric model of ecological consciousness is formed, which has conditioned the development of anthropogenic civilization and has become a source of global ecological crises. The main dominants of anthropocentric environmental conscience include a number of value orientation attitudes that determined the emergence of environmental contradictions.

One of the most important foundations of the anthropocentric worldview is the idea of progress that encompasses the spheres of production, consumption, social relations, the system of knowledge, moral norms, culture, the nature of man, etc. It is fixed and associated with the enlargement of forms of social cooperation, the development of production, and raw materials.

Another important priority of anthropocentric consciousness is the idea of the supreme value of man, which is the center of being (the basic ontological unit) and rises above nature. This provision is based on a myth according to which for man as the bearer of the mind there is no limit in the dissemination of activity. In this case, the very activity of a person in material reality is interpreted as the expansion of norms and rules into nature for its transformation in order to ensure its own security. Over time, as a derivative of material security, the concept of comfort is formed - physical, moral, social. In this idea there is a conviction in a certain evolutionary rule: the movement of a person in the direction of improving tools for his activities (progress) will provide him with a comfortable, conflictfree existence.

So in the system of anthropocentric attitudes, nature is perceived as an object of human activity, where the goal of its interaction with nature is the satisfaction of various utilitarian needs. In this logic, the notion of a "pragmatic imperative" is asserted, where it is right and normal to recognize that it benefits and maximizes the benefits to a person. [3] This position is strengthened with the help of utilitarian ethics, which received its natural spread in the conditions of the modernization and development of the market economy [9-12]. The active dissemination of "market ethics" and a passion for personal enrichment became "the driving force of the whole machine civilization" [4] However, ethical norms do not extend to interaction with the natural world, but the development of nature is conceived as a process that must be subordinated to the goals and tasks of man. Nature in anthropogenic culture is gradually becoming not a" temple, "but a" workshop ", an" environment, "a means of social progress. [4]

Thus, the new European scientific worldview became the foundation for the formulation of anthropocentric consciousness of anthropogenic civilization. The role of the "great modernizer" was assigned to the scientific and technological revolution. It was to create an "ideal world" where all the elements of nature would be completely curbed, the material universe is subordinated to man, which would determine the triumph of the all-ordering mind and control over the outside world.

However, the further development of social history and the crisis of the paradigmatic foundations of classical science have cast doubt on the principles of anthropocentrism in ecology. The ensuing era of postmodernism began with a disappointment in the scientific and technological revolution, where the destructive consequences of a number of new European landmarks that determined the nature of the environmental and social relations of the anthropogenic civilization are becoming evident. It turned out that tough industrial technologies and consumer attitude towards nature can destroy the ecosystem and thereby undermine the prospect of a person's continued existence on the Earth. In addition, it 
becomes clear that they are capable of enslaving the man himself, imposing his own mechanistic standard and norms of interaction on him. The rapidly growing influence of the industrial "megamachine" is becoming increasingly dangerous, trying to change the person himself, turning it into a functional element.

In the European system of understanding of the world since the end of the XIX century. the transformation of onto-epistemological and value systems, which caused shifts both at the level of the paradigmatic foundations of science, and in social practice, begins to be observed. In this period, a non-classical model of science is formed, where the notion of reality is based on the principles of relativism and complementarity, and also affirms the position about the dependence of the image of the world on the position of the observer in the knowledge of the microworld. The specificity of cognitive practices is determined by the features of the object of quantum-mechanical reality, which is a network of interrelated events, including the subject-observer as an element of the observable system. [5] Due to the transformation of subject-object relations, as well as under the influence of I. Kant's transcendental apriorism and practical dialectical materialism, an activity-based model of cognition is formed. In this context, a person acquires a new meaning, he is regarded as a subject of activity and an existential being responsible for his actions and constructing reality, including through science.

The formulation of new theoretical and practical problems, as well as the emergence of global environmental problems, led to the emergence of the foundations of ecocentric ecological consciousness. Among the most important priorities is the need to develop new principles of nature management, while searching for an alternative system for explaining the material world in the context of its relationship with the person and his activities. There is the emergence of a new type of scientific rationality, the criteria of which is the rejection of the cognition model as an act of contemplation of the subjective mind in the cognition of the world and the attainment of absolute truth. It is found necessary to take into account the influence of methods of cognitive activity in the description of the object, as well as the formation of epistemological practice on the basis of the principle of equality of various theoretical approaches to describing phenomena. Thus, the nonclassical picture of the world does not allow a "completely objective description of nature" [6], stimulates at the paradigm level the need to rethink the anthropocentric model of reality and initiates a gradual rejection of the central position of man in the material universe. Nature begins to be gradually perceived as equal to man and complementing him through the possibility of realizing his own activity. Recognition of the equivalence of nature determines the need for responsible attitude to their own projects and taking into account the consequences of their interference in the biosphere, including through science and technology.

In the mid-60's. there are a number of conditions that contribute to the crisis of the worldview attitude in Western society, which manifested itself in the statement of global problems, the deployment of environmental and demographic crises with irreversible destructive changes in the ecosystem. There comes an awareness of the need to transform not only the technical and technological processes, but also the mental and theoretical prerequisites that have determined the emergence of global contradictions. In these circumstances, there is a change in the paradigmatic foundations of science and the transformation of value orientation attitudes in the environmental conscience of civilization. The design of new worldviews is shaped by the ideas of postmodernism, post positivism, social constructivism. The world's picture is based on the ontology of polycentricism, which prescribes to the world the properties of mosaics and irrationality. [7, 8] Typical ontological categories are "simulacra", "hyper real", "fragmentation". [2] Cognition of the world is understood as a discursive practice, proceeding in conjunction with socio-cultural circumstances and relies on a system of conceptual-final agreements, and social norms are relative and lie in the plane of subjective preference, often unconscious. 
Postmodernism contributed to the development of the principle of ecology, where society and man are placed in a single context with the world, nature and unite in a single system of geo-bio-sociogenesis. The subject-object principle of the New Time, when the subject - "Promethean man", elevating himself above nature and culture, which should be changed at his own discretion - is opposed by the principle of co-responsibility, coownership, co-dimension. Thus, postmodernism has debunked the myth of a man towering over the world and referring to him as a means. On this basis, numerous attempts have been made to revise the Western principles of social being and mentality. [1].

In many ways, under the influence of postmodernism, the processes of globalization, the ideas of multiculturalism develop, and the science and theoretical knowledge are orientated to the principles of the diversity of cognitive procedures and images of reality. In these conditions, science is experiencing a series of cardinal changes that allow us to fix a new stage in its development - post-non-classical. V.S. Stepin singled out the following signs: the change in the nature of scientific activity associated with the revolution in the means of obtaining and storing information (the computerization of science, the merging of science with the industrial sphere), the dissemination of interdisciplinary research and integrated research programs; increasing the importance of economic and socio-political factors and objectives; the discovery of self-organizing systems; inclusion of the axiological moment in the composition of scientific theories; the use in the natural sciences of the methods of the humanities.

As the dominant cognitive practices in post-non-classical science, a dialogue and evolutionary model of epistemology is distinguished. [4] On their basis, the principle of equivalence in the interaction of man with the outside world takes shape, the desire for a deep understanding of the essential links between nature and society. In the dialogue epistemological scheme, the subject enters with the object in a relation that Habermas called "communicative action". Cognition, therefore, is here a dialogue, an act of interaction between the world and man, representing a single whole and having an indissoluble connection with each other. In evolutionism, a person is seen as part of a developing nature, and his cognitive structures are commensurate with the world and are with him in complicity. Thus, a person becomes not just an explorer, an observer of the world, but a participant in the evolutionary formation of the universe, setting new trends in its development.

Modern science, focused on the study of self-developing objects, such natural complexes, including humans, like the biosphere and the noosphere, is forced to include in the internal context what it used to endeavor to eliminate - the person. In this model of cognition, the position of an outside observer does not exist, the "human-sized" object already includes the observer and his evolving mind. Thus, a person who knows the world, as well as knowledge, procedures and tools of nature research - is all part of a selfdeveloping system and includes many perspectives and variants of development of events, for the consequences of which the person himself is responsible.

Standards and benchmarks of post-non-classical science have become a theoretical platform for the design of eco-centric consciousness, formed on the basis of some ontological principles of postmodernism, synergetic and evolutionism. In general, the existence of nature and man is conceived as a process of developing mutually beneficial cooperation. On this basis, nature is defined as an equal subject in interaction with man. In the process of nature management, it is important to maintain a balance between meeting human needs and the needs of the whole ecosystem.

There is a change in the axiological system of social consciousness, where the harmonious development of man and nature, connected with each other and representing unity in bio- and noosphere, is defined as the highest value. This sets new ethical guidelines, emphasizing the unity of moral norms and standards, which apply equally to the interaction between 
individuals in society, and to relations with nature. Central to the ethical paradigm of ecocentrism is the "ecological imperative", which affirms the principle: "only that which does not violate the existing environmental balance in nature" is right.

Particular importance is given to efficient use of natural resources and to reducing the anthropogenic load on the Earth, which is based on the need to reduce consumption and technological modernization. Environmental protection activities from the position of ecocentric environmental conscious are dictated by the need to preserve nature for its own sake, as well as for present and future generations living in harmony and balance with the outside world. Special importance is attached to science, which should create the basis for the process of building a new type of relationship between man, society and nature.

\section{Conclusion}

In general, the development of science and environmental conscious is a single interrelated process, the emergence of which occurs against the background of the dynamics of ontological, epistemological principles and values and ideological orientations characteristic of Western European society. Depending on the specifics of the paradigmatic foundations of science in a certain era, a model of a certain type of ecological consciousness was formed. Thus, classical science became the source of anthropocentric environmental conscious with an emphasis on human domination and the priority of its needs in environmental management. In the framework of non-classical and post-nonclassical models of science in the late 19th-20th centuries. The structure of ecocentric environmental conscious with the justified system of reference points to the principles of optimal and equilibrium interaction with nature, ethical attitude to it and mutually beneficial cooperation with the environment is maturing, developing and developing. This trend is dominant in the modern worldview system of Western society, but it does not fully determine social practices and environmental management processes.

\section{References}

1. T. Anderson, The origins of postmodernity. London: Verso, 1998J.Baudrillard, Simulacra and Simulations (Stanford University Press, Stanford, 1988)

2. J. E. Baugher, Ecological Consciousness, Moral Imagination, and the Framework for Strategic Sustainable Development (Emerald Group Publishing Limited, London, 2016)

3. I. V. Chernikova, Epistemology: the main problems and the evolution of approaches in the philosophy of science, (Kuzbass University, Kemerovo, 2007)

4. F. Capra, Uncommon Wisdom: Conversations with Remarkable People. (Flamingo, London, 1989)

5. J. Derrida, Globalization, Peace and Cosmopolitism in Negotiation: Interventions and Interview 1971-2001, trans (Stanford University Press, Stanford, 2002)

6. W. Heisenberg, Physics and philosophy. The revolution in modern science (Ruskin House. George Allen and Unwin Ltd. Museum Street, London. 1971)

7. V. Zolotukhin, V. Gogolin, M. Yazevich, M. Baumgarten, A. Dyagileva, IOP Conf. Series: Earth and Environmental Science, 50, 012027 (2017)

8. M. Foucalt, The Archaeology of Knowledge and The Discourse on Language. (Panteon books, New York, 1972) 
9. E.A. Gasanov, T.S. Boyko, N.S. Frolova, Economics and Innovation Management, 3, 4-8 (2018) DOI: 10.26730/2587-5574-2018-3-4-8

10. S. Zhironkin, S. Demchenko, G. Kayachev, M. Ryzhkova, O. Zhironkina, Cluster E3S Web Conf., 41, 04011 (2018)

11. S. Zhironkin, D. Khloptsov, N. Skrylnikova, I. Petinenko, O. Zhironkina, E3S Web Conf., 41, 04010 (2018)

12. S. Zhironkin, O. Aleshina, V. Gorev, Y. Gunyakov, O. Zhironkina, E3S Web of Conferences, 105, 04001 (2019) 